European Journal of Social Psychology

Eur. J. Soc. Psychol. 30, 83-100 (2000)

\title{
Conversation as a resource for influence: evidence for prototypical arguments and social identification processes
}

\author{
SCOTT A. REID* and SIK HUNG NG \\ School of Psychology, \\ Victoria University of Wellington, New Zealand
}

Abstract

Members of eight single-sex groups each consisting of three pro- and three anti-capital punishment adherents discussed their views for 30 minutes, and afterwards individually rated ingroup and outgroup members on social influence ranking, prototypicality, and social attractiveness. From the intragroup hypothesis that speaking turns are a resource for influence ( $N g$ \& Bradac, 1993), we predicted and found that turns were correlated strongly with influence in the intergroup context. Further, using self-categorization theory (SCT; Turner, 1985), we hypothesized that social identity processes would interact with turns, especially with turns obtained through interruptions. Interruptions encoded in prototypical utterances were more strongly correlated with social influence and prototypicality, but not social attraction, than interruptions encoded in non-prototypical utterances. Further, interruption attempts enacted in prototypical utterances were found to be more likely to be successful than unsuccessful in obtaining turns, while those enacted in non-prototypical utterances were more likely to be unsuccessful than successful. Additionally, interruption turns were longer when enacted in prototypical over non-prototypical utterances. Overall, the findings suggest that the power/influence of language is interactively organized and constructed around salient self-categorizations. Copyright (C) 2000 John Wiley \& Sons, Ltd.

It has been demonstrated that group members who speak the most frequently, or have the greatest proportion of a group's turns or interruptions, subsequently emerge highest in influence ranking (Bales, Strotbeck, Mills, \& Roseborough, 1951; Brooke \& Ng, 1986; Ng, Bell, \& Brooke, 1993; Ng, Brooke, \& Dunne, 1995; Scherer, 1979). This finding may be explained by assuming that conversational turns function as a resource for establishing influence. Once a turn is gained, the speaker may establish

*Correspondence to: Scott A. Reid, School of Psychology, University of Queensland, St Lucia, Queensland 4072, Australia. e-mail: scott@psy.uq.edu.au

Contract grant sponsor: Victoria University of Wellington.

CCC 0046-2772/2000/010083-18\$17.50

Received 3 March 1998

Copyright (C) 2000 John Wiley \& Sons, Ltd.

Accepted 1 April 1999 
conversational control by engaging others in a hearer role (Zajonc, 1960), maintain or change the topic, or allocate the following turn to a specific other person $(\mathrm{Ng}, 1996$; $\mathrm{Ng} \&$ Bradac, 1993). The present study addresses two related aspects of the resourceinfluence relationship that have been overlooked in existing research.

First, studies conducted within the resource paradigm have without exception employed intragroup comparative contexts. They have most commonly employed task-oriented (e.g. Bales, 1955) or ad hoc discussion groups (e.g. Ng et al., 1995). In other words, these studies have investigated conversational behaviour as occurring between individuals qua individuals. The role of group norms and identities in the resource-influence relationship have not been investigated. This is of particular concern in light of theory (e.g. Social Identity Theory, Tajfel \& Turner, 1979) and research (for a review see Hogg \& Abrams, 1988) that demonstrate the effects of social comparative context on social behaviours and evaluations. Given that social identity becomes salient in the context of other groups, it is important to consider the intergroup dimension to the resource-influence relationship.

Second, research conducted within the resource paradigm has largely neglected conversational content in favour of conversational form. It is possible, depending upon content, that only particular turns are related to influence. Self-categorization theory (Turner, 1985; Turner, Hogg, Oakes, Reicher, \& Wetherell, 1987; Turner, Oakes, Haslam, \& McGarty, 1994) suggests that turns with prototypical content should be more influential than turns with less prototypical content. Because prototypical utterances provide information about the contextually salient social identity, they are, by definition, influential (Abrams \& Hogg, 1990; Turner, 1991). Thus, turns gained using utterances high in prototypicality (high fit with social context) will bear a stronger relationship to social influence than turns gained through less prototypical utterances (low fit with social context).

\section{CONVERSATION AS A RESOURCE FOR INFLUENCE}

The idea that language functions as a resource for influence or power has beginnings in the work of Bales and colleagues (e.g. Bales, 1955; Bales et al., 1951). Bales, although initially focusing upon language content, has ultimately lent conversational form a pivotal explanatory role, Bales (1970, pp. 76-77) argued:

Who speaks how much and to whom in the group is a 'brute fact' characterizing the actual present situation. Speaking takes up time. When one member speaks, it takes time and attention from all other members of the group, some of whom may want to speak themselves. To take up time speaking in a small group is to exercise power over the other members for at least the duration of the time taken, regardless of the content... Within the small group the time taken by a given member in a given session is practically a direct index of the amount of power he has attempted to exercise in that period [emphasis added].

Indeed, Bales based these assertions on the robust finding that a speaker's conversational influence, in terms of rated quality of ideas, is strongly and positively related to the number of turns taken (e.g. Bales, 1956; Bales et al., 1951; see also Scherer, 1979; Brooke \& Ng, 1986). More recently Ng et al. $(1993,1995)$ found that post-discussion 
influence ranking correlated strongly and positively with turns, and with both successful and unsuccessful interruptions. ${ }^{1}$ A notable feature of the $\mathrm{Ng}$ et al. (1993) study was that turns gained through interruption were a more powerful predictor of influence ranking than turns gained by non-interruptive means. This finding suggests that interruptions are more power-oriented than turns achieved through noninterruptive means.

In explaining these findings, $\mathrm{Ng}$ and colleagues have taken the position, consistent with Bales (1970), that conversation is a resource for gaining influence and power. They further assumed that by speaking the longest and/or interrupting the most, a conversationalist prevents others from speaking, and thus exercises conversational control (Ng, 1996; Ng \& Bradac, 1993). Importantly, Ng and Bradac (1993) argue, contrary to Bales (1970), that utterance content plays a central role in the influence process.

\section{INTERRUPTIONS, UTTERANCE CONTENT, AND SCT}

Self-categorization theory (SCT) adds to social identity theory (e.g. Tajfel, 1978; Tajfel \& Turner, 1979, 1986) by elaborating on the social cognitive underpinnings of social identification. The process by which a social identity becomes salient depends upon an 'accessibility' by 'fit' interaction. Accessibility represents the individual's predisposition to any given categorization, and recognizes variability in the individual's experiences, expectations, motives, goals, and needs. Fit is broken into two separate components reflecting comparative and normative aspects of the categorization process. Comparative fit describes the influence of social structure, while normative fit describes the associated content.

Comparative fit is defined by meta-contrast (Campbell, 1958). A collection of individuals will be more likely to be categorized as an entity to the extent that average inter-category differences exceed average within-category differences; that is, the metacontrast ratio exceeds one (see McGarty, Haslam, Hutchinson, \& Grace, 1995). This aspect of fit is simply concerned with the relatively mechanistic aspect of stimulus representation; it is the interaction with normative fit that lends social relevance to the theory (cf. Tajfel, 1981; Oakes, 1996). Having categorized entities into distinct groups, normative fit describes the consensually represented social meaning correlated with the categorization. Comparative and normative fit jointly determine the typicality or representativeness (i.e. prototypicality) of a group. At the level of social identity, social comparisons between self and the group prototype determine self-prototypicality. That is, self is perceived in terms of the contextually salient ingroup prototype, is seen as interchangeable with other individuals who are also perceived to be prototypical of that group, and is simultaneously perceived as positively distinct from a relevant outgroup(s). Further, the ability (as contextually defined) and inclination (via category accessibility) to conform to the group prototype varies across group members.

\footnotetext{
${ }^{1}$ Roger, Bull, and Smith (1988) differentiate between successful and unsuccessful interruptions. Successful interruptions are coded when a speaker is prevented from completing an utterance, while the interrupter completes an utterance. Unsuccessful interruptions are coded when either the speaker who is being interrupted is not prevented from completing an utterance, or the attempting interrupter does not complete an utterance.
} 
Consequently, the individual highest in prototypicality is most representative of the ingroup because he or she is the most positively distinct (see Tajfel \& Turner, 1986) from the outgroup.

Importantly, prototypicality may be defined by normative consistency per se when comparative information is constant (e.g. Oakes, Turner, \& Haslam, 1991). In Oakes et al.'s second experiment, participants viewed a six-person group consisting of three arts and three science students discussing attitudes to university life. Attributions to social category membership were strongest when the ingroup and outgroup were opposed (high comparative fit), and the target speaker expressed attitudes consistent with the ingroup norm (high normative fit). In short, social category attributions were most strongly affected by comparative information when it was accompanied by normatively consistent attitudes. This finding suggests that when comparative information is constant, the more normatively consistent a speaker is, the more prototypical that speaker will be perceived.

Following the work of Oakes and colleagues (Oakes, 1987, Oakes \& Turner, 1986, 1990; Oakes et al., 1991) we propose that the ability to gain conversational turns is determined, in part, by the degree of fit between an individual's utterances and the group prototype. Prototypical utterances provide information that defines speakers and listeners within a given social context. Consequently attention will be paid to speakers who use prototypical utterances, hence lending them relatively more conversational turns than speakers whose speech is less prototypical. Speakers who use prototypical utterances will be more likely to be perceived as prototypical than other group members, and will consequently emerge higher in social influence ranking.

However, an underlying assumption in this analysis is derived from Tajfel's work on stereotyping (e.g. Tajfel, 1981; Tajfel \& Forgas, 1981). Tajfel argued that people are motivated to maintain and confirm their values and stereotypes. Applying this argument to SCT suggests that people are motivated to maintain and confirm salient self-categorizations. Indeed, this hypothesis is supported by Moreland (1985), who found that the mere mention of a category distinction, even when not actually real, lead to the maintenance of the category over time. This suggests, further, that people are motivated to attend to information that defines self in a salient social context, but not information that conflicts with their self-definition (cf. Swann, 1990). In other words, people would attend to prototypical information because it serves to confirm their social identity, while at the same time they would ignore or actively remove from the environment non-prototypical or aprototypical information.

\section{PREDICTIONS}

From resource theory, it is predicted that evaluations of a group member's social influence will increase with his or her relative conversational participation (Hypothesis 1 (H1)). Participation will be measured in terms of words, and interruptions. In the case of interruptions, from SCT we predict that a stronger positive correlation with social influence will be found for interruptions encoded in prototypical than in nonprototypical utterances (Hypothesis 2a (H2a)). The prototypicality of a speaker's interruptions (a priori defined by normative consistency) will also affect how prototypical and socially attractive he or she is perceived to be in the group. Specifically, 
it is predicted that evaluations of prototypicality will be a stronger positive function of interruptions encoded in prototypical than non-prototypical utterances (Hypothesis $2 \mathrm{~b}(\mathrm{H} 2 \mathrm{~b})$ ). Furthermore, because prototypical group members are perceived as more socially attractive than less prototypical group members (Hogg, 1992; Hogg \& Hains, 1996; Hogg, Hardie, \& Reynolds, 1995), it is predicted that evaluations of social attractiveness will be a stronger positive function of interruptions encoded in prototypical than non-prototypical utterances (Hypothesis 2c (H2c)).

Finally, following SCT and Tajfel (1981), it is predicted that prototypical interruptions will be more likely to be successful than unsuccessful in enabling the speaker to obtain turns, whereas the reverse will be true for non-prototypical interruptions (Hypothesis 3a (H3a)). That is, speakers attempting to interrupt using prototypical utterances are more likely to be attended to, whereas speakers attempting to interrupt with non-prototypical utterances will be blocked in their attempts to gain the floor. It is predicted, further, that the length of interruption turns encoded in prototypical utterances will exceed that of interruption turns encoded in non-prototypical utterances (Hypothesis 3b (H3b)). Prototypical utterances, because they are selfdefining and attract attention, will develop into longer turns than non-prototypical, or non-self-defining utterances.

\section{METHOD}

\section{Participants, design and overview}

Twenty-four male and 24 female students from year-one classes in psychology, English, chemistry, and computer science at Victoria University of Wellington were selected for participation on the basis of responses to a four-item pre-test questionnaire. The questionnaire, which was designed to create a realistic basis for social categorization, elicited 169 (61 male, 108 female) prospective participants' views on two issues: the legalization of euthanasia ('euthanasia should be legalized in New Zealand'); and capital punishment ('what is your position on the issue of capital punishment?') using 9-point scales anchored by 'for' (-4) and 'against' (4). The more extreme participants, who indicated positions less than $-1 /$ greater than 1 , were recruited for discussion sessions. ${ }^{2}$ Expression of interest in these topics ('how interesting to you is this topic?') was assessed using a 10-point scale anchored by 'very uninteresting' (1) and 'very interesting' (10). Selection preference was given to participants who indicated high interest in the topic. The capital-punishment issue showed the greatest degree of polarization, and hence, was used as the basis for intergroup social categorization and discussion.

Explicitly categorized pro- and anti-capital punishment adherents were asked to discuss the issue of capital punishment - after a short video presentation on the issue - for 30 minutes. This was followed by a questionnaire which elicited social evaluations of social influence ranking, prototypicality, and social attraction. Eight sessions, each involving three pro- and three anti-capital punishment participants of

${ }^{2}$ Lack of availability of male pro capital punishment subjects made it necessary to include a participant with an attitude position of -1 on the pre-test questionnaire. The other two members of that group indicated positions of -2 , while members of the anti-capital punishment group indicated positions of 3,3 , and 4. Despite the use of one moderate subject, the intergroup division in attitude was maintained. 
the same sex were completed, accounting for 4 hours of transcribed conversational behaviour. $^{3}$ At the conclusion of study sessions, each participant received $\$ 10$ as remuneration.

\section{Apparatus}

Conversations were recorded via wireless microphone units. The microphone was clipped below participants' chins and the transmitter unit put into a convenient pocket or held out of the way. Conversations were recorded using a six-track recorder with standard audio cassettes. These recordings were transferred to mastering quality reel-to-reel audio tapes, and transcriptions were made using an eight-track recorder. Because of the ability of this configuration of audio equipment to isolate speakers' voices on separate tracks there were few instances of coding difficulties.

\section{Procedure}

Participants were initially seated at opposite sides of a table according to pro-/anticapital-punishment adherence. Seats on one side of the table were labelled A through $\mathrm{C}$ and seats on the other side were labelled $\mathrm{D}$ through $\mathrm{F}$. Order of seating arrangement was counterbalanced with group affiliation. Identification letters, which were required for target identification in the post-discussion questionnaire, were assigned to enhance and maintain the salience of the intergroup categorization. A series of instructions were read aloud:

The reason we have brought you here today is for a discussion relevant to the issue of capital punishment. Specifically, we have selected three of you with procapital punishment attitudes and three with anti-capital punishment attitudes. In this sense there are really two groups here today. In fact your group all indicated moderate to extreme pro-capital punishment attitudes and your group moderate to extreme anti-capital punishment attitudes (experimenter points to groups)... In the first part of the study you will view a short video excerpt on the topic of capital punishment. This video contains two speakers, one a pro-capital punishment adherent, the other an anti-capital punishment adherent. These speakers give arguments for their views. As you watch this video we would like you to consider your views on this issue and perhaps consider some arguments you believe are connected with your position. For the second part of the study ... we

\footnotetext{
${ }^{3}$ The methodology employed herein, although employing interactive groups and a correlational framework, may offer several advantages over non-interactive experimental groups. First, the diachronic investigation of social interaction may provide greater insight to the process of social behaviour (Moreland, Levine, \& Cini, 1993); the description of the phenomena under investigation, rather than being constrained to a questionnaire 'snapshot,' may be observed as it naturally unfolds over time. Second, it is neither practical nor simple to recreate many group phenomena in the laboratory. Pre-existing social groups have associated histories and meanings which cannot be created on an ad hoc basis. Thus, the observation of social groups interacting over time may allow more valid and tenable explanations to be formulated. Indeed, others have argued that research using real groups in actual interaction, although more timeconsuming to conduct and problematic when trying to meet statistical assumptions such as independence of observations, may actually prove a more fruitful method to investigate small group phenomena than the experimental approach (Hogg \& Moreland, 1993; Scherer, 1979).
} 
would like you to discuss this issue... In this discussion you are in no way expected to reach consensus.

The video was edited from a 28.5 minute United States National Institute of Justice recording in which a moderator (James Q. Wilson) prompted pro- and anti-capital punishment adherents for arguments to substantiate their positions. After viewing the video, participants were asked if there were any final questions before commencement of the discussion. No questions were ever asked. To facilitate the opening of discussion, it was suggested to the participants that they may like to begin by giving their impressions of the video.

After approximately 30 minutes the discussion was terminated and the postdiscussion questionnaire distributed. Upon completing questionnaires, participants were thanked, partially debriefed, paid, and dismissed. To prevent knowledge of specific hypotheses becoming known to other participants a full debriefing and statement of results was postponed until the completion of the study.

\section{Social evaluation measures}

Social evaluations of pro- and anti-capital punishment adherents were elicited using a post-discussion questionnaire. Variables addressed in this study include social influence rank, prototypicality, and social attraction or 'depersonalized liking' (Hogg, 1992, p. 100). For each social-evaluative dimension, a single stem was supplied for each group (pro versus anti), and a rating scale for each member of the respective groups. Order of groups presented in this questionnaire (pro versus anti) and speaker labels (A-F) were counterbalanced across groups.

Social influence ranking was measured with the following pair of items: 'Rank all participants in your group [pro/anti capital punishment] including yourself in terms of how influential they were in the discussion. Please indicate your answer by writing the participants' identification letter in the space provided.' Stems worded 'most influential', 'next most influential', and 'least influential', were provided separately for both groups.

Prototypicality was measured using the following pair of items (cf. Haslam, Oakes, McGarty, Turner, \& Onorato, 1995): 'With reference to the [pro-capital/anti-capital] punishment group here today, how typical or representative of this group's position were the views of ...?' Each group member was rated using a 9-point Likert scale anchored by 'unrepresentative' (1) and 'representative' (9) according to group membership.

Social attraction was assessed for all participants except self, and was measured using the following pair of items: 'How likeable in your opinion are the [pro/anti] capital punishment participants here today?' Each group member was rated using a 9-point scale anchored by 'unlikeable' (1) and 'likeable' (9), according to group membership.

\section{Coding of conversational behaviour}

Conversational behaviour was coded with respect to turns, interruptions (successful \& unsuccessful), and normative consistency (consistent/inconsistent/neutral). A turn 
was defined as an utterance comprising one or more words spoken by the same speaker until a switch of speakership occurred. Back-channel minimal responses (e.g. mhmm, yeah) were not coded as turns. In the case of two or more speakers starting to speak simultaneously, a turn was coded to any of the speakers who produced an utterance that could be content coded. Interruptions were coded as successful when (1) the interrupter completed an utterance and (2) prevented the interruptee from completing an utterance. When one or both of these conditions were not met, an unsuccessful interruption was coded. Interruptions also included silent interruptions (i.e. where there is no overlap in speech, but there is still clearly a successful interruption; see Ferguson, 1977; Roger et al., 1988), but not simultaneous starts.

The prototypicality of utterances associated with successful and unsuccessful interruptions was coded with respect to normative consistency. Normative consistency (cf. Oakes et al., 1991) was defined as the correlation between an utterance and the contextually salient ingroup norm (i.e. pro versus anti-capital punishment adherence). Specifically, the prototypicality of utterances was coded in terms of the content of the utterance with respect to the speaker's ingroup norm (consistent/inconsistent/neutral). Utterances that were consistent with the speaker's ingroup norm were coded as prototypical (see Example 1 below), utterances that are not consistent with arguments for either position were coded as non-prototypical (i.e. neutral, see Example 2 below), while utterances that are inconsistent with the speaker's ingroup norm (i.e. consistent with the outgroup norm) were coded as aprototypical.

As very few instances of aprototypical utterances were encountered $(n=18$, or 1.70 per cent of sample), this variable was dropped from analyses. That few aprototypical utterances were made suggests that comparative fit was constant, and hence, that normative consistency was a valid measure of prototypicality.

The utterances of three randomly selected speakers were independently coded by a trained individual unaware of the hypotheses. Using Cohen's Kappa it was found that successful and unsuccessful interruptions $(\kappa=0.82)$ and judgements of the prototypicality of utterances $(\kappa=0.82)$ were coded with a high level of agreement.

Example 1 presents a case where an anti-capital punishment speaker successfully interrupts a pro-capital punishment speaker. The anti speaker argues that as capital punishment will not work in practice it should not be implemented. This argument is clearly consistent with being anti-capital punishment, and inconsistent with being pro-capital punishment. Because this argument defines group positions, it is coded as normatively consistent and hence prototypical of the speaker's ingroup.

\section{Example 1. Successful prototypical interruption:}

Pro: well eh that is that is the legal system that's not behind what the principle supports [the principle is you do]

Anti :

[so is is it] saying there in theory it's ok but in practice it's never going to work out so why implement it

In Example 2 a pro-speaker successfully interrupts an anti speaker. The pro speaker offers the information that in America there have been working factories in prisons for fifty years. This argument is simply a statement of information, and is not incompatible with either pro or anti views. Given that the statement is not 
consistent with an argument for or against capital punishment, this utterance is coded as normatively neutral, and hence non-prototypical of the speaker's ingroup. Note, however, that although the pro speaker's utterance is consistent with the task of discussing views, it is irrelevant to the definition of intergroup differences.

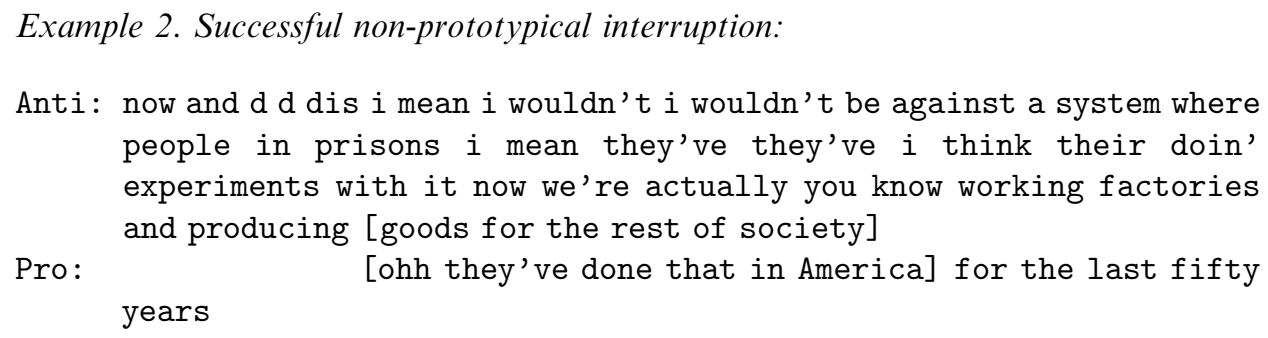

\section{RESULTS}

\section{Ingroup and outgroup scores}

Pro- and anti-capital punishment group responses were recoded to form an ingroupoutgroup distinction. ${ }^{4}$ Anti participants' social evaluations of anti participants, and pro participants' social evaluations of pro participants on any given post-discussion variable were coded as ingroup social evaluation indices. On the other hand, anti participants' ratings of pro members, and vice versa, were coded as outgroup social evaluation indices. A participant's scores on ingroup social evaluation indices were represented as the mean of social evaluations assigned to him or her by all ingroup members, and by all outgroup members in the case of outgroup social evaluation indices. Perceived ingroup social influence, prototypicality, and social attraction were scored as the mean of ratings received from ingroup members (i.e. pro from pro, anti from anti), whereas perceived outgroup social influence, prototypicality, and social attraction were scored as the mean ratings received from outgroup members (i.e. pro from anti, and anti from pro).

\section{Transformations of variables}

Although speaking time was held constant across groups, there were differences in the relative frequencies of turns across groups. To control for variations between groups in frequencies of conversational participation, the frequency of each group member's words, turns, interruptions, and unsuccessful interruptions were expressed as a proportion of the ingroup total. Note that although we could have expressed conversational behaviour as a proportion of the intergroup total (i.e. total of six speakers), we preferred to use the ingroup level (three speakers) because it corresponds to the level of coding used for the post-discussion variables.

\footnotetext{
${ }^{4} \mathrm{We}$ choose to retain the differentiation between ingroup and outgroup social evaluations and conversational behaviours although it is not relevant to our hypotheses. This allows us to retain consistency between the social context and our coding, and to test for any referent effects that might qualify our hypotheses.
} 
The social evaluation measures of perceived prototypicality and social attraction, which were continuous variables measured on a Likert response format, might be affected by non-independence due to groups. For these variables, we examined the extent of group dependence by using a one-way MANOVA with conversation group (coded with 16 levels) as a treatment variable, and ingroup and outgroup prototypicality and social attraction as dependent variables (see Kenny \& Judd, 1986). A significant multivariate group effect was found ( $F$ (Wilks' lambda) $(60,115)=3.07, p<0.001)$. Significant univariate effects were found for ingroup prototypicality $(F(15,32)=3.26, \quad p<0.005), \quad$ and ingroup $(F(15,32)=7.38$, $p<0.001)$ and outgroup $(F(15,32)=2.11, p<0.05)$ social attraction. A marginally significant univariate effect was also found on outgroup prototypicality $(F(15,32)=1.90, p=0.063)$. Given that dependence was present, the group variable was used as a covariate in analyses involving these variables.

In the case of the social influence ranking dependent variables, non-independence due to between-groups variation is not a source of bias because each group's mean rank is a constant. In spite of this it is possible is that the ranking procedure, per se, might bias our correlations. To illustrate, if a rater in a three-person group could discriminate one speaker as more influential while viewing the remaining two speakers as equally influential, the forced ranking of the three speakers would artificially separate the two less influential speakers. These imposed and non-veridical rankings might then produce a spurious correlation with another variable (in other words, a non-significant correlation may be accepted as significant - a type 1 error). With only one rater, it is not possible to know if the ranking procedure imposes an artificial distinction or not. However, as indicated, our rankings were based upon a mean ranking received by three ingroup raters or three outgroup raters. If all three raters achieve high consensus in their rankings, it suggests that the ranking procedure is veridical. To measure consensus in the influence rankings, the number of agreements with an individual's overall mean ranking were summed and divided by the total possible to produce a proportional measure of group consensus. Percentage levels of agreement indicated a high level of shared perception for both ingroup ( 71.7 per cent) and outgroup (75.3 per cent) social influence rankings. Given this high level of consensus, the probability of (wrongly) accepting non-significant correlations as significant is attenuated.

Furthermore, the procedure of using mean received rankings implies that where there is low consensus, the distribution of rankings within the group becomes flat, which in turn would reduce the possibility of finding a spurious correlation.

Finally, to guard against making a type 1 error in our analyses, we have adopted a conservative alpha level $(\alpha=0.01)$.

\section{Social influence}

To assess H1 (that evaluations of a group member's social influence will increase with his/her relative conversational participation), Pearson correlations were calculated (see Table 1). To reiterate, the mean influence ranking received by ingroup and outgroup members constituted two measures of social influence in the group. These mean rankings were then correlated with a speaker's relative proportion of his or her ingroup's total words, turns, successful and unsuccessful interruptions. However, 
these measures of conversational participation were intercorrelated. For this reason, words, turns, successful, and unsuccessful interruptions were subjected to reliability analysis. These four measures of conversational participation produced a highly reliable scale $(\alpha=0.90)$.

Confirming $\mathrm{H} 1$, the four-item measure of conversational participation correlated strongly with both ingroup $(r=0.72, p<0.001)$ and outgroup $(r=0.76, p<0.001)$ social influence.

It was expected that the positive correlations with social influence would be stronger for interruptions encoded in prototypical than in non-prototypical utterances (H2a). As shown in Table 2, this was the case in all four comparisons. To test this hypothesis formally, a series of regressions were carried out in which prototypical and non-prototypical interruptions were entered as predictors of ingroup and outgroup social influence. Analyses were conducted separately for ingroup and outgroup social influence, and for successful and unsuccessful interruptions. All four analyses clearly supported H2a. Interruptions encoded in prototypical utterances emerged as more powerful predictors of perceived social influence than interruptions encoded in non-prototypical utterances: this was the case for successful interruptions on ingroup $(\beta=0.53, t(41)=4.21, p<0.0001 ;$ versus $\beta=0.12, t(41)=0.98$, $p=0.33)$ and on outgroup $(\beta=0.59, t(41)=4.91, p<0.0001$; versus $\beta=0.06$, $t(41)=0.55, p=0.58)$ social influence; and for unsuccessful interruptions on ingroup $(\beta=0.69, t(41)=5.84, p<0.0001 ;$ versus $\beta=-0.11, t(41)=-0.90$, $p=0.37)$, and on outgroup $(\beta=0.72, t(41)=6.61, p<0.0001$; versus $\beta=0.01$, $t(41)=0.09, p=0.93)$ social influence.

\section{Prototypicality}

To assess $\mathrm{H} 2 \mathrm{~b}$ (that interruptions encoded in prototypical utterances will be evaluated more prototypical than interruptions encoded in non-prototypical

Table 1. Correlations between social influence and conversational participation

\begin{tabular}{lcc}
\hline & \multicolumn{2}{c}{ Influence } \\
\cline { 2 - 3 } & Ingroup & Outgroup \\
\hline Four-item participation scale & $0.72^{*}$ & $0.76^{*}$ \\
Words & $0.75^{*}$ & $0.82^{*}$ \\
Turns & $0.66^{*}$ & $0.68^{*}$ \\
Successful interruptions & $0.56^{*}$ & $0.53^{*}$ \\
Unsuccessful interruptions & $0.56^{*}$ & $0.67^{*}$ \\
\hline
\end{tabular}

Note. ${ }^{*} p<0.001, N=48$, one-tailed tests.

Table 2. Correlations between interruptions encoded in prototypical and non-prototypical utterances with social influence

\begin{tabular}{lcccccc}
\hline & \multicolumn{2}{c}{ Ingroup influence } & & \multicolumn{2}{c}{ Outgroup influence } \\
\cline { 2 - 3 } \cline { 5 - 6 } Interruption content & Proto & Non-proto & & Proto & Non-proto \\
\hline Successful interruptions & $0.55^{*}$ & 0.21 & & $0.60^{*}$ & 0.16 \\
Unsuccessful interruptions & $0.65^{*}$ & 0.11 & & $0.72^{*}$ & 0.24 \\
\hline
\end{tabular}

Note. $* p<0.001$, one-tailed tests. 
utterances) a set of hierarchical regression analyses was conducted. In these analyses, ingroup and outgroup social evaluations of prototypicality were treated as dependent variables while prototypical and non-prototypical interruptions were treated as predictors. To control effects of non-independence due to groups on the dependent variables, the 16 conversational groups were dummy variable coded as 15 binary variables (see Cohen \& Cohen, 1983), and were entered in the first step of hierarchical regressions. Our focal variables were entered in the second step (see Tabachnick \& Fidell, 1989). Analyses were conducted separately for successful and unsuccessful interruptions. After controlling groups $(F(15,32)=1.90, p=0.06)$, interruptions encoded in prototypical utterances emerged as more powerful predictors of perceived outgroup prototypicality than interruptions encoded in non-prototypical utterances: this was the case for successful interruptions $(\beta=0.41, t(31)=3.66, p<0.01$, versus $\beta=-0.07, t(31)=-0.56, p=0.58)$ and unsuccessful interruptions $(\beta=0.41$, $t(31)=3.72, p<0.01$ versus $\beta=0.12, t(31)=1.07, p=0.30)$.

However, after controlling groups $(F(15,32)=3.26, p<0.01)$, ingroup prototypicality failed to be predicted by either successful prototypical or non-prototypical interruptions $(\beta=0.12, t(31)=1.06, \quad p=0.30$ versus $\beta=0.08, t(31)=0.65$, $p=0.52$ ), or unsuccessful prototypical versus non-prototypical interruptions $(\beta=25, t(31)=2.28, p=0.03$ versus $\beta=0.09, t(31)=0.83, p=0.41)$.

\section{Social attraction}

To investigate $\mathrm{H} 2 \mathrm{c}$ the hierarchical regression procedure was repeated, again with groups controlled, using ingroup social attraction and outgroup social attraction as dependent variables. No significant equations emerged.

\section{Turn taking}

This set of analyses was designed to test $\mathrm{H} 3 \mathrm{a}$ and $\mathrm{H} 3 \mathrm{~b}$. Recall that $\mathrm{H} 3 \mathrm{a}$ stated that prototypical interruptions would be more likely to be successful than unsuccessful, whereas the reverse would be true for non-prototypical interruptions. To test this hypothesis a 2(interruption content: prototypical/non-prototypical) by 2(interruption outcome: successful/unsuccessful) within-subjects ANOVA was conducted, and expected to yield a significant content by interruption outcome interaction. The results showed, first, a significant interruption outcome main effect $(F(1,47)=42.07$, $p<0.001)$ : there were more unsuccessful $(M=5.84)$ then successful $(M=2.49)$ interruptions. This unanticipated effect reflects the fact that, more often than not, speakers made several attempts to gain the floor before succeeding. The only other significant effect was the interruption outcome by content interaction $(F(1,47)=25.28, p<0.01)$. The cell means showed, contrary to H3a, that prototypical utterances were more unsuccessful $(M=5.00)$ than successful $(M=3.77)$, while, consistent with predictions, non-prototypical interruptions tended to be more unsuccessful $(M=6.68)$ than successful $(M=1.21)$.

In the light of the greater base-rate likelihood of interruptions to be unsuccessful than successful (i.e. the main effect of interruptions outcome), it is necessary to retest H3a by controlling for base rate differences in interruption outcome. Each speaker's 
Table 3. Mean frequencies of successful and unsuccessful interruptions encoded in prototypical and non-prototypical utterances

\begin{tabular}{lcc}
\hline & Prototypical & Non-prototypical \\
\hline Successful & $12.85(10.31)$ & $4.26(4.92)$ \\
Unsuccessful & $6.72(4.58)$ & $9.51(7.68)$ \\
\hline
\end{tabular}

Notes. Standard deviations in parentheses. The utterance prototypicality by interruption success interaction is significant, $F(1,47)=41.92$, $p<0.01$. Post-hoc Scheffe tests showed that the two prototypical cell means differed significantly from one another, as did the two nonprototypical cell means.

proportion of his or her group's unsuccessful interruptions were divided by the ratio of unsuccessful ( $n=376)$ to successful $(n=142)$ interruptions (2.65). This effectively removes the main effect of interruption outcome $(F(1,47)=0.18, p=0.67)$, hence providing an unbiased test of H3a. A 2(interruption content: prototypical/nonprototypical) by 2(interruption outcome: successful/unsuccessful) within-subjects ANOVA conducted on the transformed data showed two significant effects (see Table 3). An interruption content main effect revealed that there were more interruption turns encoded in prototypical $(M=9.78)$ than non-prototypical ( $M=6.88)$ utterances, $(F(1,47)=8.14, p<0.01)$. Importantly, the critical content by interruption outcome interaction was significant, $F(1,47)=41.92, p<0.01$. Confirming H3a, prototypical utterances led to more successful $(M=12.85)$ than unsuccessful $(M=6.72)$ interruptions $(F(1,47)=24.28, p<0.01$ with Scheffé $)$, whereas non-prototypical utterances led to more unsuccessful $(M=9.51)$ than successful $(M=4.26)$ interruptions $(F(1,47)=17.81, p<0.01$ with Scheffé).

$\mathrm{H} 3 \mathrm{~b}$ stated that prototypical interruptions would develop into longer turns than non-prototypical interruptions. To test this hypothesis, two matched-pair $t$-tests were conducted on the number of words expressed within successful and unsuccessful interruptions under prototypical versus non-prototypical utterances. Confirming H3b, successful interruptions $(t(47)=5.45, p<0.001)$ were longer when encoded in prototypical $(M=133.71)$ over non-prototypical $(M=31.06)$ utterances; and unsuccessful interruptions $(t(47)=5.16, p<0.001)$ were longer when encoded in prototypical $(M=164.21)$ over non-prototypical utterances $(M=48.94)$. These findings were replicated when the frequencies of words were expressed as a proportion of the ingroup total.

\section{DISCUSSION}

Replicating and extending previous work conducted in intragroup contexts (e.g. $\mathrm{Ng}$ et al., 1993, 1995), the present findings indicate that conversation also functions as a resource for influence in an intergroup context. Confirming $\mathrm{H} 1$, conversational participation was moderately to highly correlated with perceived ingroup and outgroup social influence. Quite simply, the greater a speaker's participation in group discussion, the greater the resulting perceived influence. In addition, the current study highlights the dependence of this relationship on social context. 
Strong evidence was obtained for H2a. perceived social influence was correlated more strongly with interruptions that were enacted in prototypical utterances than with interruptions enacted in non-prototypical utterances. Consistent with SCT, influential speakers are those whose utterances (as enacted in successful and unsuccessful interruptions) most consistently represent the norm of their group. By doing so, these speakers represent social context in group differentiated terms, and consequently place themselves in a position to best define and delineate group identities. That this is the case is reinforced by the finding that interruptions encoded in non-prototypical utterances were not as strongly correlated with perceived influence. Thus, language functions as a resource for influence most strongly when the speaker's language represents the contextually relevant identity in a manner consistent with the salient self-categorization.

Furthermore, the current study illustrates how speakers may establish or negotiate influence. The relevant findings show that prototypical utterances lead to more successful than unsuccessful interruptions, while non-prototypical utterances lead to more unsuccessful than successful interruptions (H3a). Moreover, interruptions were longer when encoded in prototypical over non-prototypical utterances (H3b). These findings are suggestive of an interactionally negotiated influence process. The ability to gain a turn depends upon the speaker producing a prototypical utterance, to which listeners orient their attention: speakers who use prototypical utterances are granted speaking rights, whereas speakers who use non-prototypical utterances are blocked in their attempts to gain the floor. Although the listener determines how the speaker orients his or her speech, and whether or not the speaker's contribution will be considered important and become developed in subsequent turns (cf. Diamond, 1996; $\mathrm{Ng}, 1996$ ), all conversationalists are oriented to social context in the first instance. That is, turn taking depends upon a 'local management system' (Sacks, Schegloff, \& Jefferson, 1974, p. 725), but this system is situated in and constrained by social context.

To summarize thus far, the evidence suggests that influence is derived from two patterns of communication in the group. Influential speakers have (1) a disproportionate share of turns and (2) a greater share of the group's prototypical utterances (but see below for a discussion of the relationship between prototypical utterances and participation). The evidence suggests further, and critically, that the pattern of speech from influential speakers is organized at a contextual rather than individual level, and that it is interactionally constructed.

Furthermore, in support of $\mathrm{H} 2 \mathrm{~b}$, social evaluations of outgroup members' prototypicality (but not social evaluations of ingroup members' prototypicality) were more strongly correlated with successful and unsuccessful interruptions enacted in prototypical than non-prototypical utterances. This finding suggests that there was disagreement within ingroups as to what constituted an ingroup prototypical utterance, but some agreement as to what constituted an outgroup prototypical utterance. There is, therefore, evidence that the group prototypes to emerge from conversation were not entirely constrained by social context. Instead of prototypicality being a pre-given representation which people conform to or diverge from, as implied in SCT, it would appear that the prototype is activated or even created on the spot, through language.

Evidence for $\mathrm{H} 2 \mathrm{c}$ - that prototypical interruptions would predict social attraction over non-prototypical interruptions-was not obtained. That not all regressions yielded the predicted solutions may in part reflect the subtlety of the difference between 
prototypical and non-prototypical utterances. Were it possible to compare prototypical and aprototypical forms, more robust solutions might have been obtained.

Having drawn these conclusions, alternative explanations for our findings should be considered. One possibility is that the relevance of utterances to the task at hand, and not utterance prototypicality, moderated the relationship between conversational participation and influence. If this is the case, then it might be that participants were not responsive to social context, only to task demands. However, we at least partially accounted for task relevancy in our coding scheme. Although non-prototypical utterances included ideas independent/irrelevant to the task at hand, such utterances were comparatively rare. In fact, non-prototypical utterances were on the whole taskrelevant, but irrelevant to the definition of intergroup difference (see Example 1 in Method section). Moreover, a corollary of the task-relevancy interpretation suggests that our findings, not being responsive to the intergroup context, would be identical in an intragroup social context. In fact, based on SCT, we also predict identical effects in an 'intragroup' context. Even in an intragroup context, the discussion of an ingroup position remains an example of intergroup behaviour because the definition of an ingroup position requires, for its existence, a distinct outgroup position (see Turner et al., 1987).

A second possibility is that the advantage of prototypical over non-prototypical utterances in predicting social influence is an artefact of participation rate. That is, prototypical utterances might be more strongly correlated with overall participation than non-prototypical utterances, and that this overall participation difference accounts for the stronger predictive power of prototypical interruptions. Indeed, rerunning our analyses for $\mathrm{H} 2 \mathrm{a}$, with overall participation covaried, reveals that overall participation removes the advantage of prototypical over non-prototypical interruptions in predicting social influence. However, this is not to say that our findings are spurious.

There are two ways in which we can model the relationship between conversational participation, prototypical utterances, and social influence. A first model predicts a direct relationship between participation and social influence, as above. A second model, as endorsed currently, is that prototypical utterances lead to participation which in turn predicts social influence. In fact, we have some evidence for this mediational model. From $\mathrm{H} 3 \mathrm{a} / \mathrm{H} 3 \mathrm{~b}$ we found, that prototypical utterances would be more likely to lead to successful interruptions/longer speaker turns while nonprototypical utterances would be more likely to lead to unsuccessful interruptions/ shorter speaking turns. These findings suggest that the reason overall participation predicts social influence beyond interruptions is that non-interruptive turns are most likely prototypical in content.

To conclude, contrary to Bales' (1970) view that turns are inherently power oriented regardless of content, the current study furnishes evidence that power or influence in group discussion is negotiated around utterance content which functions to confirm the salient social context, such that only group-defining utterances become influential. Ironically, a similar statement was made by Bales and Slater (1955): 'the quality of overt participation of a particular member is thus presumably constrained, in part, by the way in which the things he would like to say or do "fits in" to a larger latent structure of ideas, feelings, and expectations as that structure develops over a long time span of interactions' (pp.273-274). We now have evidence that the conversational control assumed by powerful or influential speakers is contingent upon language 
content, but that content realizes meaning and is constructed around salient selfcategorizations.

\section{ACKNOWLEDGEMENTS}

This research was funded in part by a Victoria University of Wellington grant to the first author. We would like to thank Sandra Lowe for transcribing the conversations in three of the groups, and to Jo White for recoding utterances for reliability coding. We would also like to thank Julie Duck, Jim Cameron, and three anonymous reviewers for their insightful comments on an earlier draft of this paper. A version of this paper was presented at the Society of Australasian Social Psychologists in Christchurch, New Zealand, 1998.

\section{REFERENCES}

Abrams, D. \& Hogg, M. A. (1990). Social identification, self-categorization and social influence. European Review of Social Psychology, 1, 195-228.

Bales, R. F. (1955). The equilibration problem in small groups. In A. P. Hare, E. F. Borgatta \& R. F. Bales (Eds), Small groups: Studies in social interaction (pp. 424-457). New York: Borzoi.

Bales, R. F. (1956). Task status and likeability as a function of talking and llistening in decision making groups. In L. D. White (Ed.), The state of the social sciences (pp. 148-161). Chicago, IL: University of Chicago Press.

Bales, R. F. (1970). Personality and interpersonal behaviour. New York: Holt, Reinhart, and Winston.

Bales, R. F. \& Slater, P. E. (1955). Role differentiation in small decision making groups. In T. Parsons \& R. F. Bales (Eds), Family socialization and interaction process (pp. 259-306). Glecoe, IL: Free Press.

Bales, R. F., Strodtbeck, F. L., Mills, T. M. \& Roseborough, M. (1951). Channels of communication in small groups. American Sociological Review, 16(4), 461-468.

Brook, M. E. \& Ng, S. H. (1986). Language and social influence in small conversational groups. Journal of Language and Social Psychology, 5(3), 201-210.

Campbell, D. T. (1958). Common fate, similarity and other indices of the status of aggregates of persons as social entities. Behavioural Science, 3, 14-25.

Cohen, J. \& Cohen, P. (1983). Applied multiple regression/correlation analysis for the behavioural sciences (2nd edn). Hillsdale, NJ: Erlbaum.

Diamond, J. (1996). Status and power in verbal interaction. Amsterdam: John Benjamins.

Ferguson, N. (1977). Simultaneous speech, interruptions and dominance. British Journal of Social and Clinical Psychology, 16, 295-302.

Haslam, S. A., Oakes, P. J., McGarty, C., Turner, J. C. \& Onorato, R. (1995). Contextual changes in the prototypicality of extreme and moderate outgroup members. European Journal of Social Psychology, 25(5), 509-531.

Hogg, M. A. (1992). The social psychology of group cohesiveness: From attraction to social identity. London: Harvester Wheatsheaf.

Hogg, M. A. \& Abrams, D. (1988). Social identifications: A social psychology of intergroup relations and group processes. London \& New York: Routledge.

Hogg, M. A. \& Hains, S. C. (1996). Intergroup relations and group solidarity: Effects of group identification and social beliefs on depersonalized attraction. Journal of Personality and Social Psychology, 70(2), 295-309. 
Hogg, M. A., Hardie, E. A. \& Reynolds, K. H. (1995). Prototypical similarity, selfcategorization and depersonalized attraction: A perspective on group cohesiveness. European Journal of Social Psychology, 25, 159-177.

Hogg, M. A. \& Moreland, R. L. (1993). Studying social processes in small groups. British Journal of Social Psychology, 32, 107-110.

Kenny, D. A. \& Judd, C. M. (1986). Consequences of violating the independence assumption in analysis of variance. Psychological Bulletin, 99(3), 422-431.

McGarty, C., Haslam, S. A., Hutchinson, K. J. \& Grace, D. M. (1995). Determinants of perceived consistency: The relationship between group entativity and meaningfulness of categories. British Journal of Social Psychology, 34, 237-256.

Moreland, R. L. (1985). Social categorization and the assimilation of 'New' group members. Journal of Personality and Social Psychology, 48(5), 1173-1190.

Moreland, R., Levine, J. \& Cini, M. (1993). Group socialization: The role of commitment. In M. A. Hogg \& D. Abrams (Eds), Group motivation: Social psychological perspectives (pp. 105-129). New York: Harvester-Wheatsheaf.

Ng, S. H. (1996). An essay in honour of Henri Tajfel. In W. P. Robinson (Ed.), Social identity: The developing legacy of Henri Tajfel (191-215). Oxford: Butterworth-Heineman.

Ng, S. H., Bell, D. \& Brooke, M. (1993). Gaining turns and achieving high influence ranking in small conversational groups. British Journal of Social Psychology, 32, 265-275.

Ng, S. H. \& Bradac, J. J. (1993). Power in language: Verbal communication and social influence. Newbury Park, CA: Sage.

Ng, S. H., Brooke, M. \& Dunne, M. (1995). Interruption and influence in discussion groups. Journal of Language and Social Psychology, 14(4), 369-381.

Oakes, P. J. (1987). The salience of social categories. In J. C. Turner, M. A. Hogg, P. J. Oakes, S. D. Reicher \& M. Wetherell (Eds), Rediscovering the social group: A Self-Categorization Theory (pp. 117-141). Oxford and New York: Blackwell.

Oakes, P. J. (1996). The categorization process: Cognition and the group in the social psychology of stereotyping. In W. P. Robinson (Ed.), Social Identity: The developing legacy of Henri Tajfel. Oxford: Butterworth-Heineman.

Oakes, P. J. \& Turner, J. C. (1986). Distinctiveness and the salience of social category memberships: Is there an automatic perceptual bias toward novelty? European Journal of Social Psychology, 16, 325-344.

Oakes, P. J. \& Turner, J. C. (1990). Is limited information processing capacity the cause of social stereotyping? European Review of Social Psychology, 1, 111-135.

Oakes, P. J., Turner, J. C. \& Haslam, S. A. (1991). Perceiving people as group members: The role of fit in the salience of social categorizations. British Journal of Social Psychology, 30, 125-144.

Roger, D., Bull, P. \& Smith, S. (1988). The development of a comprehensive system for classifying interruptions. Journal of Language and Social Psychology, 7(1), 27-34.

Sacks, H., Schegloff, E. \& Jefferson, G. (1974). A simplest systematics for the organization of turn-taking for conversation. Language, 50, 696-735.

Scherer, K. R. (1979). Voice and speech correlates of perceived social influence in simulated juries. In H. Giles \& R. St Clair (Eds), Language and social psychology (pp. 88-120). Oxford: Blackwell.

Swann, W. B. (1990). To be adored or to be known? The interplay of self-enhancement and self-verification. In E. T. Higgins \& R. M. Sorrentino (Eds), Handbook of motivation and cognition: Foundations of social behavior (Vol. 2, pp. 408-448). New York: Guilford Press.

Tabachnick, B. G. \& Fidell, L. S. (1989). Using multivariate statistics (2nd edn). New York: HarperCollins.

Tajfel, H. (1978). Differentiation between social groups: Studies in the social psychology of intergroup relations. London: Academic Press.

Tajfel, H. (1981). Social stereotyping and social groups. In J. C. Turner \& H. Giles (Eds), Intergroup behaviour (pp. 144-167). Oxford: Blackwell.

Tajfel, H. \& Forgas, J. P. (1981). Social categorization: Cognitions, values and groups. In J. P. Forgas (Ed.), Social cognition: Perspectives on everyday understanding (pp. 113-140). London: Academic Press. 
Tajfel, H. \& Turner, J. C. (1979). An integrative theory of intergroup conflict. In W. G. Austin \& S. Worchel (Eds), The social psychology of intergroup relations (pp. 33-47). Monterey, CA: Brooks/Cole.

Tajfel, H. \& Turner, J. C. (1986). The social identity theory of intergroup behaviour. In S. Worchel \& W. G. Austin (Eds), Psychology of intergroup relations (pp. 7-24). Chicago, IL: Nelson-Hall.

Turner, J. C. (1985). Social categorization and the self concept: A social cognitive theory of group behaviour. In E. J. Lawler (Ed.), Advances in group processes (Vol. 2, pp. 77-122). Greenwich, CT: JAI Press.

Turner, J. C. (1991). Social influence. Milton Keynes: Open University Press.

Turner, J. C., Hogg, M. A., Oakes, P. J., Reicher, S. D. \& Wetherell, M. S. (1987). Rediscovering the social group: A self-categorization theory. Oxford: Basil Blackwell.

Turner, J. C., Oakes, P. J., Haslam, S. A. \& McGarty, C. (1994). Self and collective: Cognition in social context. Personality and Social Psychology Bulletin, 20(5), 454-463.

Zajonc, R. B. (1960). The process of cognitive tuning in communication. Journal of Abnormal and Social Psychology, 61(2), 159-167. 